\title{
BLOOD VARIABLES ASSOCIATED WITH SURVIVAL IN CANINE CONGESTIVE HEART FAILURE PATIENTS
}

\author{
A. NEMEC SVETE ${ }^{1}$, B. VERK ${ }^{1}$, P. JAZBEC KRIŽMAN ${ }^{2}$, \\ N. DRUZHAEVA ${ }^{1}$, N. BOHANEC ${ }^{3} \&$ A. DOMANJKO PETRIČ ${ }^{1}$ \\ ${ }^{1}$ University of Ljubljana, Veterinary Faculty, Small Animal Clinic, Ljubljana, \\ Slovenia; ${ }^{2}$ National Institute of Chemistry, Ljubljana, Slovenia; ${ }^{3}$ Institute for \\ Biostatistics and Medical Informatics, University of Ljubljana, \\ Faculty of Medicine, Ljubljana, Slovenia
}

\begin{abstract}
Summary
Nemec Svete, A., B. Verk, P. Jazbec Križman, N. Druzhaeva, N. Bohanec \& A. Domanjko Petrič, 2020. Blood variables associated with survival in canine congestive heart failure patients. Bulg. J. Vet. Med., 23, No 2, 257-261.

Our study aimed to investigate the blood variables: coenzyme $\mathrm{Q}_{10}, \mathrm{~N}$-terminal pro-B-type natriuretic peptide (NT-proBNP), electrolytes, cholesterol, triglyceride, glutathione peroxidase, white blood cell, neutrophil, lymphocyte and monocyte counts and relative numbers of neutrophils, lymphocytes and monocytes that may be associated with survival of dogs in congestive heart failure (CHF). Twentyone client-owned dogs in CHF were included in the study. Cox regression analysis showed significant association only between NT-proBNP blood concentration and survival.
\end{abstract}

Key words: blood variables, cardiovascular diseases, coenzyme $\mathrm{Q}_{10}$, dogs, N-terminal proB-type natriuretic peptide, survival

In human patients with decompensated heart failure, some basic laboratory parameters, such as increased white blood cell (WBC) and neutrophil counts, higher serum C-reactive protein, glucose, blood urea nitrogen and creatinine concentrations, and higher aspartate aminotransferase activity are significantly associated with in-hospital deaths (Ostrowska et al., 2017). Furthermore, plasma coenzyme $Q_{10}$ $\left(\mathrm{CoQ}_{10}\right)$ concentration was found as an independent predictor of mortality in human patients with chronic heart failure (Molyneux et al., 2008). Coenzyme $\mathrm{Q}_{10}$ is an essential cofactor in oxidative phosphorylation in mitochondria and a powerful antioxidant (Littarru \& Tiano, 2007).

Various factors associated with survival in dogs with mitral valve disease (MVD; Serres et al., 2009; Moonarmart et al., 2010; de Madron et al., 2011; Hezzell et al., 2012; Sargent et al., 2015) or di- 
lated cardiomyopathy (DCM; Slupe et al., 2008; Martin et al., 2010; NoszczykNowak, 2011) were investigated. Evaluated factors consisted mostly of echocardiographic and electrocardiographic variables, clinical findings and N-terminal pro-B-type natriuretic peptide (NT-proBNP). However, the data on association of blood variables with survival in dogs with congestive heart failure (CHF) are sparse, with the exception of NT-proBNP. Moreover, antioxidant parameters, such as plasma $\mathrm{CoQ}_{10}$ and intracellular antioxidant enzyme, glutathione peroxidase (GPX), and some basic laboratory parameters, such as total and differential white blood cell counts, have not been evaluated as factors associated with survival, yet.

The aim of this study was to find out which of the patients' blood variables measured at admission: plasma $\mathrm{CoQ}_{10}$ (lipid-standardised $\mathrm{CoQ}_{10}$ ), serum NTproBNP, sodium $(\mathrm{Na})$, potassium $(\mathrm{K})$, chloride $(\mathrm{Cl})$, total cholesterol and triglyc- eride concentrations, whole blood GPX activity, WBC, neutrophil, lymphocyte and monocyte counts and relative numbers of neutrophils, lymphocytes and monocytes were associated with survival of canine CHF patients (ISACHC II and III classes; International Small Animal Cardiac Health Council) due to MVD and DCM.

Twenty-one client-owned dogs (Table 1) with MVD $(n=17)$ or DCM $(n=4)$, were included in the study and classified into ISACHC II or III groups. Cardiovascular patients included in our study were of the following breeds: Mixed breed dogs $(n=5)$, Cavalier King Charles Spaniel $(n=3)$ and one dog of each breed: Doberman Pinscher, Great Dane, German Boxer, German Shepherd, Golden Retriever, Tibetan Terrier, Dogue de Bordeaux, Jack Russell Terrier, English Cocker Spaniel, Leonberger, Dalmatian, Miniature Schnauzer and Wire-Haired Dachshund. Cardiovascular disease was confirmed on the basis of history and re-

Table 1. Baseline characteristics of canine congestive heart failure patients and laboratory results of five variables used in Cox proportional-hazards models. Results are presented as median and interquartile range (IQR) in the case of non-normal distribution of the data or as mean \pm standard deviation (SD) in the case of normal distribution of the data

\begin{tabular}{ll}
\hline & Patients $(\mathrm{n}=21)$ \\
\hline Sex (female/male) & $4 / 17$ \\
ISACHC II/ ISACHC III & $13 / 8$ \\
Cardiac diseases (MVD/DCM) & $17 / 4$ \\
Age (years); mean \pm SD & $9.9 \pm 2.6$ \\
Weight $(\mathrm{kg})$; median, IQR & $16.8,10.5-35.2$ \\
NT-proBNP (nmol/L), mean $\pm \mathrm{SD}$ & $5.540 \pm 2.763$ \\
WBC $\left(\mathrm{x} 10^{9} / \mathrm{L}\right)$, mean $\pm \mathrm{SD}$ & $11.6 \pm 3.2$ \\
Neutrophil count $\left(\mathrm{x} 10^{9} / \mathrm{L}\right)$, mean $\pm \mathrm{SD}$ & $8.48 \pm 2.5$ \\
$\mathrm{~K}(\mathrm{mmol} / \mathrm{L})$, mean $\pm \mathrm{SD}$ & $4.06 \pm 0.52$ \\
$\mathrm{CoQ}{ }_{10}(\mathrm{mg} / \mathrm{L})$, median, IQR & $1.07,0.51-1.39$ \\
\hline
\end{tabular}

ISACHC - International Small Animal Cardiac Health Council classification for cardiac disease; MVD - mitral valve disease; DCM - dilated cardiomyopathy; NT-proBNP - N-terminal pro-B-type natriuretic peptide; $\mathrm{WBC}$ - white blood cell count; $\mathrm{K}$ - potassium; $\mathrm{CoQ}_{10}$ - coenzyme $\mathrm{Q}_{10}$. 
Table 2. Hazard ratios (HR) and corresponding 95\% confidence intervals (CI) and P values.

\begin{tabular}{lcc}
\hline Variable & HR, $(95 \%$ CI for HR) & P value \\
\hline CoQ $_{10},(\mathrm{mg} / \mathrm{L})$ & $0.74(0.39,1.38)$ & 0.34 \\
WBC $\left(\times 10^{9} / \mathrm{L}\right)$ & $1.09(0.93,1.27)$ & 0.29 \\
Neutrophil count $\left(\times 10^{9} / \mathrm{L}\right)$ & $1.13(0.95,1.36)$ & 0.18 \\
K $(\mathrm{mmol} / \mathrm{L})$ & $2.72(0.78,9.44)$ & 0.12 \\
NT-proBNP $(\mathrm{nmol} / \mathrm{L})$ & $1.27(1.07,1.52)$ & $<0.01$ \\
\hline
\end{tabular}

$\mathrm{CoQ}_{10}$ - coenzyme $\mathrm{Q}_{10}$; WBC - white blood cell count; $\mathrm{K}$ - potassium; NT-proBNP - N-terminal pro-B-type natriuretic peptide.

sults of a clinical examination, radiographic examination of the thorax, standard ECG examination, and echocardiography with 2-dimensional, M-mode, colour, and spectral Doppler modes (Vingmed System Five, General Electric Healthcare, USA). Blood samples for determination of selected blood variables were collected at admission. Haematological variables were measured with automated haematology analyser ADVIA 120 (Siemens, Germany), total cholesterol and triglyceride with automated biochemistry analyser RX-Daytona (Randox, Great Britain) and electrolytes $(\mathrm{Na}, \mathrm{K}, \mathrm{Cl})$ with Ilyte analyser (Instrumentation Laboratory, USA). Whole blood GPX activity and plasma $\mathrm{CoQ}_{10}$ (lipid standardised $\mathrm{CoQ}_{10}$ ) and serum NT-proBNP concentrations were measured as reported previously (Svete et al., 2017). All procedures complied with applicable governmental regulations (Animal Protection Act University of Ljubljana Republic of Slovenia, 43/2007).

Data were analysed using $\mathrm{R}$ programming language. Significance level was set to $5 \%$. Survival time was counted from the day of admission to the time of death or euthanasia. A broader exploratory analysis was made from which the variables of interests were identified. Considering there was no censoring present in the data, the initial correlation between time-to-death and a set of 16 blood variables was evaluated using Spearman's rank correlation coefficient. Five variables of interest: $\mathrm{K}(\mathrm{r}=-0.37, \mathrm{P}=0.09), \mathrm{CoQ}_{10}$ $(\mathrm{r}=0.12, \quad \mathrm{P}=0.61), \quad \mathrm{WBC} \quad(\mathrm{r}=-0.15$, $\mathrm{P}=0.51)$, neutrophil count $(\mathrm{r}=-0.21$, $\mathrm{P}=0.36)$ and NT-proBNP $(\mathrm{r}=-0.562$, $\mathrm{P}=0.008$ ) were further analysed using Cox proportional-hazards models. Hazard ratios (HR), 95\% confidence intervals (CI) and corresponding $\mathrm{P}$ values were calculated. Obtained $\mathrm{P}$ values were not adjusted as they do not refer to an inference and will only serve as a basis for future research. During the study period, all dogs died or were euthanised due to their cardiac disease. Median survival time was 11.6 months (range: 0.1-73.7 months).

In canine $\mathrm{CHF}$ patients, low plasma $\mathrm{CoQ}_{10}$ concentration was associated with the greater severity of the disease (Svete et al., 2017). Furthermore, we demonstrated leukocytosis and neutrophilia in dogs with severe, i.e. decompensated CHF (Domanjko Petrič et al., 2018). Contrary to our expectations, $\mathrm{CoQ}_{10}$, as well as WBC, neutrophil count and $\mathrm{K}$, were not significantly associated with the survival of our patients (Table 2). The lack of significant effect of these variables on survival might be due to low number of patients included in the present study and 
inclusion of two diseases or may be inherent to dogs with CHF. In the study of Molyneux et al. (2008), where low plasma $\mathrm{CoQ}_{10}$ concentration was an independent predictor of mortality, high number (236) of severely symptomatic human heart failure patients with median ejection fraction of $37 \%$ were included. We assume that the phase of decompensation in particular played a key role in the process of decreasing plasma $\mathrm{CoQ}_{10}$ concentration.

A significant association was found only between NT-proBNP and survival (Table 2), which has already been reported in canine cardiovascular patients (Serres et al., 2009; Moonarmart et al., 2010, Noszczyk-Nowak, 2011; Hezzell et al., 2012). According to the Cox model in our study, an increase of NT-proBNP for 1 unit $(1 \mathrm{nmol} / \mathrm{L})$, increased the risk for death by $27.5 \%(p=0.0063)$, which is in general agreement with results of Serres et al. (2009). The increase in risk for death, obtained in our study, was lower when compared with reported values in dogs with MVD (Moonarmart et al., 2010; Hezzell et al., 2012). According to our opinion, the difference might be attributed to difference in NT-proBNP assay methods used, as well as to mixed severity of studied dogs in those two studies, while in our study, only CHF dogs were included. Additionally, lower HR value obtained in the current study might be attributed to the lack of survival outcomes in our study.

According to the results of our study, we may conclude that the investigated blood variables, with the exception of NTproBNP, were not associated with survival of CHF patients. Our results warrant further studies on association of blood variables with survival in a larger group of severely affected canine CHF patients with a single disease in order to confirm the results of the present study.

\section{ACKNOWLEDGEMENTS}

The authors acknowledge the financial support of the Slovenian Research Agency.

\section{REFERENCES}

Borgarelli, M., R. A. Santilli, D. Chiavegato, G. D'Angolo, R. Zanatta, A. Mannelli \& A. Tarducci, 2006. Prognostic indicators for dogs with dilated cardiomyopathy. Journal of Veterinary Internal Medicine, 20, 104-110.

Domanjko Petrič, A., T. Lukman, B. Verk \& A. Nemec Svete, 2018. Systemic inflammation in dogs with advanced-stage heart failure. Acta Veterinaria Scandinavica, 60, 20.

Hezzell, M. J., Boswood, A., Y. M. Chang, W. Moonarmart, K. Souttar \& J. Elliott, 2012. The combined prognostic potential of serum high - sensitivity cardiac troponin I and N-terminal pro-B-type natriuretic peptide concentrations in dogs with degenerative mitral valve disease. Journal of Veterinary Internal Medicine, 26, 302-311.

Littarru, G. P. \& L. Tiano, 2007. Bioenergetic and antioxidant properties of coenzyme Q10: recent developments. Molecular Biotechnology, 37, 31-37.

Martin, M. W., M. J. Stafford Johnson, G. Strehlau \& J. N. King, 2010. Canine dilated cardiomyopathy: A retrospective study of prognostic findings in 367 cases. Journal of Small Animal Practice, 51, 428-436.

Molyneux, S. L., C. M. Florkowski, P. M. George, A. P. Pilbrow, C. M. Frampton, M. Lever \& A. M. Richards, 2008. Coenzyme Q10: An independent predictor of mortality in chronic heart failure. Journal of American College of Cardiology, 52, 1435-1441.

Moonarmart, W., A. Boswood, V. Luis Fuentes, D. Brodbelt, K. Souttar \& J. Elliott, 2010. N-terminal pro B-type natriuretic peptide and left ventricular diameter independently predict mortality in dogs 
with mitral valve disease. Journal of Small Animal Practice, 51, 84-96.

Noszczyk-Nowak, A., 2011. NT-pro-BNP and troponin I as indicators of mortality in dogs with heart failure. Polish Journal of Veterinary Science, 14, 551-556.

Ostrowska, M., A. Ostrowski, M. Luczak, M. Jaguszewski, P. Adamski, J. Bellwon, A. Rynkiewicz \& M. Gruchala, 2017. Basic laboratory parameters as predictors of inhospital death in patients with acute decompensated heart failure: Data from a large single-centre cohort. Kardiologia Polska, 75, 157-163.

Sargent, J., R. Muzzi, R. Mukherjee, S. Somarathne, K Schranz, H. Stephenson, D. Connolly, D. Brodbelt \& V. L. Fuentes, 2015. Echocardiographic predictors of survival in dogs with myxomatous mitral valve disease. Journal of Veterinary Cardiology, 17, 1-12.

Serres, F., J. L. Pouchelon, L. Poujol, H. P. Lefebvre, C. Trumel, C. C. Daste, C. C. Sampedrano, V. Gouni, R. Tissier, G. Hawa \& V. Chetboul, 2009. Plasma Nterminal pro-B-type natriuretic peptide concentration helps to predict survival in dogs with symptomatic degenerative mitral valve disease regardless of and in combination with the initial clinical status at admission. Journal of Veterinary Cardio$\log y, \mathbf{1 1}, 103-121$.
Slupe, J. L., L. M. Freeman \& J. E. Rush, 2008. Association of body weight and body condition with survival in dogs with heart failure. Journal of Veterinary Internal Medicine, 22, 561-565.

Svete, A. N., B. Verk, A. Seliškar, K. Tomsič, P. J. Križman \& A. D. Petrič, 2017. Plasma coenzyme Q10 concentration, antioxidant status, and serum N-terminal probrain natriuretic peptide concentration in dogs with various cardiovascular diseases and the effect of cardiac treatment on measured variables. American Journal of Veterinary Research, 78, 447-457.

Paper received 17.01.2019; accepted for publication 06.03.2019

\section{Correspondence:}

Assoc. prof. Aleksandra Domanjko Petrič, DVM, MSc, PhD

University of Ljubljana, Veterinary Faculty, Small Animal Clinic Gerbičeva 60, 1000 Ljubljana, Slovenia Tel.: + 38614779285 e-mail: aleksandra.domanjko@vf.uni-lj.si 